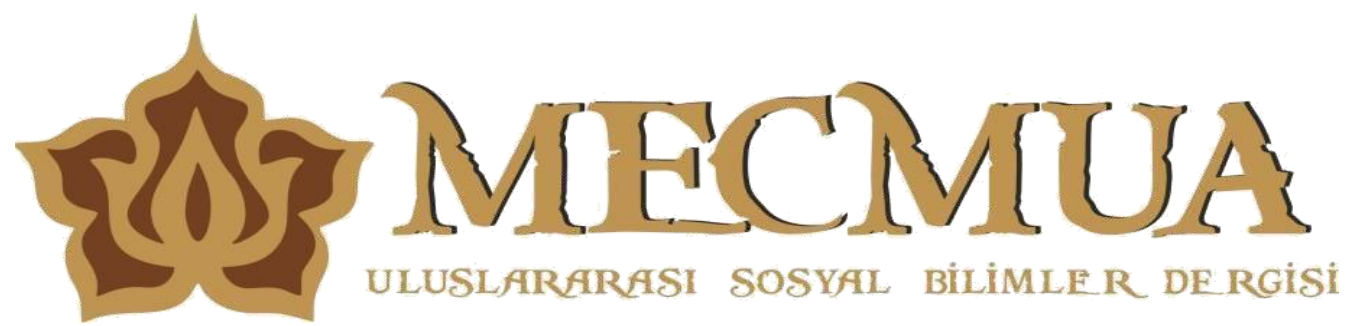

Mecmua Uluslararasi Sosyal Bilimler Dergisi [International Journal Of Social Sciences]

Uluslararası Hakemli E-Dergi/ Referee International E-Journal

Yil: 6, Sayı: 11, ISSN:2587-1811 Yayımlanma Tarihi: 30.03.2021

Metinlerarasılık Bağlamında Mevlânâ'nın Mesnevî'si İle Beydebâ'nın Kelile ve Dimne'si
In The Context Of Intertextuality Mesnevi of Mevlana With Beydeba's Kalila and Dimna

\title{
Neslihan DOKUMACI
}

ID Adıyaman Üniversitesi, Lisansüstü Eğitim Enstitüsü, Türk Dili ve Edebiyatı Bölümü, Doktora Öğrencisi, Adıyaman, Türkiye.dokumacineslihan@gmail.com

\section{Makale Bilgisi / Article Information}

Makale Türü: Araştırma Makalesi

DOI: mecmua.895171

Yükleme Tarihi: 11.03.2021

Kabul Tarihi: 29.03.2021

Yayımlanma Tarihi: 30.03.2021

Sayı: 11

Sayfa: $135-151$
Article Information: Research Article

DOI: mecmua.895171

Received Date: 11.03 .2021

Accepted Date: 29.03.2021

Date Published: 30.03 .2021

Volume: 11

Sayfa: $135-151$

\section{Atıf / Citation}

DOKUMACI, N. (2021). Metinlerarasılık Bağlamında Mevlânâ'nın Mesnevî’si İle Beydebâ'nın Kelile ve Dimne'si. MECMUA - Uluslararast Sosyal Bilimler Dergisi ISSN: 2587-1811 Y1l: 6, Sayı: 11, Sayfa: 135-151

DOKUMACI, N. (2021). In The Context Of Intertextuality Mesnevi of Mevlana With Beydeba's Kalila and Dimna. MECMUA - International Journal Of Social Sciences ISSN: 2587-1811 Year: 6, Volume: 11, Page: 135-151 


\title{
METINLERARASILIK BAĞLAMINDA MEVLÂNÂ'NIN MESNEVî'Sİ İLE BEYDEBÂ'NIN KELIILE VE DIMNE'Sİ
}

\author{
In The Context Of Intertextuality Mesnevi of Mevlana With Beydeba's \\ Kalila and Dimna
}

\begin{abstract}
ÖZ
Klasik edebiyatımız zengin bir kültürel kaynağa sahiptir. Bu kültürün bileşenlerini; bir taraftan din ve tasavvuf kültürü, diğer taraftan sosyal hayat oluşturmaktadır. Din ve tasavvufun inanç ve sosyal hayatlarını belirlediği kültür, toplumların yaşamlarından beslenerek kendine aldığı değerlerle bunu sağlamıştır. $\mathrm{Bu}$ değerler muhteva, üslup ve davranış etkilemesidir. $\mathrm{Bu}$ anlamda Doğu kültürlerinde klasik kültür içinde birbirine tevarüs eden ve birbirini etkileyen metinlerarasıllk ilişki yaygındır. Kendisini daha çok tahkiye metoduyla ve sembolik bir anlatım metoduyla ifade eden bu üslup, birçok esere ilham kaynağı olmuştur.
\end{abstract}

Arap, Fars ve Türk edebiyatlarında çeviri, adaptasyon, etkilenme bakımlarından bu tür bir yaygın etkiye sahip eser Hint menşeli Beydebâ'nın Kelile ve Dimne adlı eserdir. Kelile ve Dimne, iki bin yıl evvel Beydebâ isimli bir Hint bilgesi tarafından Debșelim adlı Hint kralına Sanskritçe olarak sunulmuştur. Eserin Sanskritçe'deki adı "Karataka ve Damanaka" dır. Bu isimler iki çakalın adidır.

Kaynakları itibariyle zengin olan Mesnevî, Türk ve Fars kültürü içinde önemli bir yere sahiptir. Mesnevî'ye kaynaklık eden eserlerden biri de Kelile ve Dimne'dir. Mesnevî'de Kelile ve Dimne'den doğrudan alıntı yapılmış üç hikâye vardır. Bu çalışmada Kelile ve Dimne ile Mesnevî eserleri tanıtılacak ve Mevlânâ'nın Mesnevî’sinin Kelile ve Dimne ile olan metinlerarsılık ilișkisi ele alınacaktır. Ayrıca, Mesnevî şerhlerinde Kelile ve Dimne'nin geçtiği hikâyelere şârihlerin yaptığ 1 şerhler değerlendirilecektir.

Anahtar Kelimeler: Metinlerarasılık, Klasik Hikâye, Mesnevî, Kelile ve Dimne, Şerh.

\begin{abstract}
Our classical literature has a rich cultural resource. Components of this culture; On the one hand, religion and sufism culture, on the other hand, constitute social life. The culture, in which religion and sufism determine their belief and social lives, has ensured this with the values it has acquired from the lives of societies. These values are content, style and behavior influence. In this sense, intertextuality relationship that inherits and affects each other in classical culture is common in Eastern cultures. This style, which expresses itself mostly with the type term method and a symbolic expression method, has been a source of inspiration for many works.

The work that has such a widespread effect in terms of translation, adaptation and influence in Arabic, Persian and Turkish literatures is Beydebâ's Kalila and Dimna of Indian origin. Kalila and Dimna was presented in Sanskrit two thousand years ago to the Indian king named Debșelim by an Indian scholar named Beydebâ. The name of this work in Sanskrit is "Karataka and Damanaka". These names are the names of two jackals.
\end{abstract}

Mesnevî, which is rich in resources, has an important place in Turkish and Persian culture. One of the works that serve as a source for Mesnevî is Kalila and Dimna. There are three stories directly quoted from Kalila and Dimna in Mesnevî. In this study The works of Kalila and Dimna and Mesnevî will be introduced and the relationship between the texts of Mevlânâ's Mesnevî with Kalila and Dimna will be discussed. In addition, the commentaries made by the commentators on the stories of Kalila and Dimna in the Mesnevî commentaries will be evaluated.

Keywords: Intertextuality, Classical Story, Mesnevî, Kalila and Dimna, Commentary. 


\section{Giriş}

Kültür; kendi muhtevası, unsurları ve disiplinleri zaman içinde oluşturulurken, kendi yaşantısı ile beraber, dinî, coğrafî ve kültürel ilişki içinde oldukları milletlerden doğal olarak etkilenir. Bu etkilenmenin boyutları kültür tarihi çalışmalarının ve alt disiplinlerin bir alanı olarak incelenmektedir. Edebiyat tarihi de eserlerin bu etkileme ve etkilenme tarihini ele almaktadır.

İslam kültür ve edebiyatının tesiri altında ortaya çıkan klâsik Türk edebiyatı, başlangıçta İran edebiyatının etkisinde kalmıştır. İlerleyen zamanla birlikte şairlerin hayal dünyasını, estetik hususiyetler bakımından örnek bir model gösteren bu edebiyat; şairlerin yetişmesi, eserlerin ortaya konması ve Türkçe kaynaklar ile bir zihniyet ve estetik gelenek oluşturmuştur. İslam medeniyetinin temel kaynaklarını yerli unsurlarla yoğuran bu edebiyat, 19. yy'ın ikinci yarısına kadar varlığını sürdürmüş, etkisini ise hâlâ sürdürmektedir. Bu sebeple "Türk-İran münasebetleri; dinî, siyasî, coğrafî, ekonomik vb. etkenlerle şekillenen, kültürel ve edebi uzun bir geçmişe sahiptir. İran'da hüküm süren hanedanların çoğunun Türk kökenli olması Fars edebiyatında Türk kültürünün izlerini bırakmış, bu izler Fars klasik edebiyatının şekillenmesinde etkili olmuştur.” (Tuğluk 2009: 13).

Doğu kültürü, tarihsel süreç içerisinde İslam'dan beslenerek karşımıza çıkmaktadır. Kadim kültürlere sahip olan coğrafyalar, çoğunlukla kültürleriyle de kader birlikteliği yapmıştır. Bu münasebetle ortaya sadece bir ilişki ya da etkilenme değil, ilişikler ağ diyebileceğimiz geniş çerçevede ele alınabilecek bir durum ortaya çıkmıştır. Arap, Hint ve Türk edebiyatlarında işlenen ortak konular, nazım şekillerindeki ortaklık ve benzerlik, türler noktasındaki etkilenmeler bu ilişki ağını ortaya koyan somut örneklerdir. Eserlerin birbirine kaynaklık etmesi ise, belki bu etkilenme boyutunun en önemli hususlarından biridir.

Klâsik Türk edebiyatı geleneğinde şiir ve düzyazı alanında birçok eser verilmiştir. Özellikle şiir alanında dîvânlar ve mesnevîler şairlerin ortaya koyduğu özgün eserlerdir.

Bu anlamda Mevlânâ'nın Mesnevî'si incelenmesi gereken eserlerden biridir. Fars şiirinin kaside ve gazelle birlikte üç temel nazım şeklinden biri olan mesnevî, iki beyitlik şiirlerden binlerce beyitlik müstakil kitaplara kadar değişik uzunluklarda kaleme alınmıştır. Mesnevîlerin her beytinin kendi arasında kafiyeli oluşu (aa / bb / cc ...) ve genellikle aruzun kısa kalıplarıyla yazılmış olması konu bütünlügünü sağlama ve anlatım açısından şairlere büyük kolaylıklar sağlamıştır. "Klâsik Türk şiirinde nazım şekilleri, belli konuları ele alan birer form olmakla birlikte; edebî, kültürel, toplumsal vb. birçok alanda, yazıldıkları dönem ile ilgili bilgiler içeren birer eser konumundadırlar. Uzun yazılabilmeleri, birçok bölümden oluşabilmeleri itibariyle zengin eserler olan mesnevîler, şair tipini çizmede yardımcı olacak önemli kaynaklar olarak karşımıza çıkmaktadır.” (Tuğluk 2020: 619-635). 
İslam ve Doğu kültürlerine vukûfiyeti, tasavvuf tarihi içinde şahıs ve eserleriyle ihraz ettiği önem Mevlânâ’nın ve eserlerinin kaynakları açısından incelemenin önemini göstermektedir. Mesnevî şerhleri gözden geçirildiğinde Mesnevî’nin pek çok kaynaktan yararlandığı görülmektedir.

Mesnevî’nin geniş yelpazedeki kaynaklarından biri de Kelile ve Dimne'dir. Mevlânâ, Mesnevî'de Kelile ve Dimne'yi farklı bağlamlarda anlatımına katkı sağlamak, anlatımı teyit etmek, anlatımına yeni bir ufuk açmak açısından aynı zamanda kendi üslubuna, anlatımına da uygun olması hasebiyle kullanmıştır. Mesnevî'deki Kelile ve Dimne etkisini tespit etmek için Mesnevî’nin altı cildi de hassas bir şekilde gözden geçirilmiş, konu ile ilgili yapılan çalışmalar ele alınmıştır. Çalışmada daha çok metinlerarasılık kuramından yola çıkılarak bir çalışma yapılmıştır. Çalışmada şârihlerin Mesnevî'de geçen Kelile ve Dimne ile ilgili hikâyeleri nasıl ele aldıkları incelenmiş, her hikâye birebir bütün unsurları bakımından karşılaştırılmıştır.

\section{Metinlerarasılık ve Mukayeseli Edebiyat}

"Her edebî metin, doğal olarak belirli bir kültürden doğar. Bu durum her metnin aslında kültür ortaklığı yönünden alıntılar mozaiği olarak okunması gerektiğini, başka metinleri de içine alabildiğini ifade eder. Buradan metinlerarası ilişkiler (intertextuality) kavramı doğar." (Mengi 2005: 594). Her metin başka metinlerle veya metnin dış dünyasındaki olgularla ilişki içindedir. Bir metnin doğduğu coğrafya ve bu coğrafyada yaşayan insanların gelenekleri ve görenekleri, tarihi ve kültürleri o metnin dokusunu oluşturur. Metin bu değerlerle beraber kendi içerisinde gelişir, büyür ve bir anlam dünyası oluşturur. Bir metnin, tüm bu gelişmelerden bağımsız bir şekilde düşünülmesi mümkün değildir. Bu bağlamda metinlerarasılık metnin kaçınılmazıdır. Metnin tamamlayıcı dokusudur.

İlmî araştırmaların temelinde analiz ve sentez vardır. Senteze ulaşmanın yolu da mukayeseden geçer. Klyas etme, ölçme, ölçü, karşılaştırma ve bazı cihetleri ortak iki ayrı unsurun birbiriyle karşılaştırılması demek olan mukayese, edebiyata taşındığında "mukayeseli edebiyatı" da karşılar. (Çapan 2003: 226). Birbirinden farklı iki edebiyat mukayese edilebileceği gibi, aynı millî edebiyatın farklı devirlerinde vücut bulmuş eser ve hareketlerini de mukayese etmek mümkündür. Buna göre mukayeseli edebiyat; bir edebiyatın bir başkası veya başkalarıyla mukayesesi ve edebiyatın insan ifadesinin diğer alanları ile karşılaştırılmasıdır. (Enginün 1999: 17). "Karşılaştırmalı edebiyat biliminin temelinde de öteki bilim dallarında olduğu gibi, karşılaştırma metodu vardır." (Aytaç 2003: 15). Birçok farklı edebiyat veya kültürün karşılaştırılması şeklinde tanımlanırken sonraki yıllarda disiplinler arası bir alan olarak hem birbirine yakın bağları incelemekte hem de farklı alanlar açısından mukayese edilmektedir. 


\section{Mevlânâ Celâleddîn-i Rûmî ve Mesnevî}

Asıl adı Celâleddin olan Mevlânâ, Rebîülevvel 604'te (30 Eylül 1207) Horasan'ın Belh şehrinde dünyaya gelmiştir. Mevlânâ'nın babası Bahâeddin Veled, Belh'e yerleşmiş bir ulemâ ailesine mensuptur. Bahâeddin Veled, Konya'da Altınapa Medresesi'nde iki y1l müderrislik yaptıktan sonra 18 Rebîülâhir 628 (23 Şubat 1231) tarihinde vefat etmiştir.

Şems-i Tebrîzî ile karşılaşması Mevlânâ'nın hayatında bir dönüm noktası oluşturur. Dîvân-1 Kebîr'deki şiirlerin büyük bir kısmını da bu dönemde söylemiştir. Dîvân-1 Kebîr'in tamamlanmasının ardından İslâm kültürünün en yaygın ve en önemli eserlerinden biri olan Mesnevî takip eder.

Mevlânâ Celâleddîn-i Rûmî’nin tasavvuf anlayışını içeren İslâm kültürünün en önemli eserlerinden biri olan Mesnevî, Mevlânâ Celâleddîn-i Rûmî'nin altı cilt ve yaklaşık 25.700 beyitten meydana gelen Farsça bir eseridir. Mevlânâ'nın seyr ü sülûkte bulunanlar için irşad kitabı olarak tanıttığı Mesnevî, bir metnin insan ve toplumu nasıl dönüştürebileceğine örnek teşkil eder. Eserin ne zaman yazılmaya başlandığı konusunda kesin bilgi bulunmamaktadır. Şârihlere göre Mesnevî adı hem kitabın şekline hem muhtevasına delâlet etmektedir. "Mevlânâ eserine Keşşâfü'l-Kur'ân ve Fikh-1 Ekber gibi isimler vermiştir. Şârihler bu isimlerin Mesnevi'nin özelliklerini yansitan nitelemeler olduğunu belirtir." (Karaismailoğlu 2002: 210-212).

\section{Beydebâ ve Kelile ve Dimne Hikâyesi}

Beydebâ MÖ. I. yy'da yaşamış olan ünlü bir Hint yazarıdır. Beydebâ'nın gerçek ismi ve nereli olduğu üzerinde birçok farklı görüşlerin olduğu söylenilmektedir. Doğum ve ölüm yeri konusunda kaynaklarda kesin bir bilgi bulunmamaktadır.

Kelile ve Dimne, fabl türünün en önemli eserlerinden biridir. Eser, hükümdarlara yol göstermek, devlet dairesinde olanlara yardımcı olmak amacıyla yazılmış bir hikâye ve masal kitabıdır. Adı Arapça metinde Beydebâ şeklinde verilen bir filozofla Debşelim adındaki hükümdar arasında geçen konuşmalar şeklinde kaleme alınmıştır. Kitabı oluşturan masalların kahramanları hayvanlardır. Eserin ana kaynağı, bir hükümdarın oğullarını eğitmek amacıyla yazıldığı ve aynı şekilde genişletilmiş versiyonları da birtakım hükümdarların istekleriyle hazırlandığı için kitabın konusu daha çok ailevî ve siyasî terbiye üzerinedir. Eserde yeri geldikçe ferdî ahlâka da göndermeler yapılır. Eser, "Arapça neşirlerindeki yaygın tertibe göre Süryânîce tercümesinde bulunmayan, dolayısıyla kitaba sonraki asırlarda eklendiği anlaşılan dört mukaddime ile beş kitaptan meydana gelmiştir. Kitaplar da toplam on dört bölüme ayrılmaktadır." (Karaismailoğlu 2002: 210-212).

"Kitabın içindeki en önemli ve hacimli hikâyesinin iki kahramanı olan çakalların adı Kelile ve Dimne (Sanskritçe Karataka ve Damanaka, Eski Süryanî tercümesinde Kalilag ve Damnag) bütün kitaba adını vermiştir.” (Brockhelm 1977: 
552). Bidpay Hikâyeleri olarak da tanınan bu eser, çok az kitabın eriştiği bir üne sahip olmuştur. "Gerek doğuda ve gerek batıda hem orijinalinden ve hem de ilk çevirilerinden çeşitli dillere çevirileri yapılmış ve bunu diğerleri takip etmiştir." (Toska 1989: 2-3-5).

\section{Mesnevî ile Kelile ve Dimne Arasındaki Ortak Konular ve Motiflerin İşlenişindeki Edebî ve Düşünsel Akıma Ait Farklılıklar}

Mesnevî’de tespit edilen hikâye ve masalların bir kısmının Hint kökenli olduğu bilinmektedir. Çünkü Mesnevî'de, Kelile ve Dimne hikâyesinden doğrudan tespit edilen üç hikâye yer almaktadır. Mevlânâ, Hint kaynaklarından aldığı bu hikâye ve masalları iki yoldan (sözlü anlatımlar veya yazılı metinler) biri aracılığıyla öğrenildiği düşünülmektedir. Onun Kelile ve Dimne'yi bizzat okumuş olması kuvvetli bir ihtimaldir. Mevlânâ'nın Kelile ve Dimne'den aldığı masalların olay örgüsünün özüne fazla müdahale etmeden, onları tasavvuf anlayışının çeşitli cephelerini yansıtacak biçimde değiştirdiği, metinlere eklemeler yaptığı tespit edilir. Bugün bilinen en eski hikâye, masal ve fablların, çok sonraki çağlarda üretilen metinlerden bir kısmında aynen veya değiştirilmiş şekilleriyle yer aldığı görülür.

Kelile ve Dimne ile Mesnevî arasındaki ortak konular ve motifleri açısından değerlendirildiğinde her iki hikâyede de benzer başlıklar, konular ve motifler olduğu görülür. Meselâ Kelile ve Dimne'deki “üç balık” ile Mesnevî'deki “üç balığın halleri ve sonları" adlı bu tür hikâyelerdendir.

4.1. Kelile ve Dimne'deki Şekli: Adı “üç balık” tır. (Alpay 1973: 81-82). Hikâyenin özeti aşağıda şu şekilde geçmektedir:

Üç Balık Hikâyesinin Özeti: Naklederler ki içinde üç balığın yaşadığı bir göl varmış: Biri akıllı, biri daha akıllı, biri de âciz. Bu kimsenin yaklaşamayacağ 1 yüksek bir yerde imiş, yakınında da akan bir nehir varmış. O nehrin yanından iki avcı geçmiş, aralarında ağlarıyla göle dönüp içindeki balıkları avlamak için sözleşmişler. Balıklar da onların sözlerini işitmiş. Balıkların en akıllısı avcının sözlerini işitince işkillenmiş, korkmuş ve hiçbir tarafa gitmeden suyun nehirden girdiği yerden çıkıp gitmiş. Akıllı balık, avcılar gelene kadar yerinde kalmış, onları görüp de ne yapmak istediklerini anlayınca suyun girdiği yerden çıkmak üzere gitmiş, bir de ne görsün, avcılar orayı kapamış. Bu vaziyette kendi kendine şöyle demiş: "İhmal ettim, işte ihmal neticesi budur. Acaba bu halden kurtulmanın çaresi nedir? Gerçi acele ve telaş içinde tedbirin faydası yoktur. Fakat akıllı kimse düşüncenin getireceği faydadan ümit kesmez, hiçbir şeyde me'yus olmaz, düşünmeyi ve gayret sarf etmeyi elden bırakmaz." Sonra balık ölmüş gibi görünerek suyun üzerine çıkmış, bazen sırtı üzerine bazen karnı üzerine dönmüş. Avcılar onu alarak nehirle göl arasındaki yere koymuşlar. Balık nehre atlayarak kurtulmuş. Âciz ve ahmak balığa gelince şuraya gitmiş, buraya gitmiş ve nihayet avlanmış. 
3.2. Mesnevî’deki Şekli: "Üç balığın halleri ve sonları" -A inatçı! Bu içinde üç balık bulunan gölcügün hikâyesine benzer. Kelile'de okumuşsundur ama o kabuktan ibarettir, bu anlatışımızsa canın tâ içidir. (Karaismailoğlu 2007: 376377).

Üç Balığın Halleri ve Sonları Hikâyesinin Özeti: Birkaç balık avcısı gölün yanından geçtiler ve oradaki balıkları gördüler. Balıkçılar ağ getirmek için koştular. Balıkların akılları başlarında olduğu için işi anladılar. İçlerinden akıllı olanı yolu tuttu. $\mathrm{O}$ güç, zor aşılır yolu ister istemez aştı. Kendi kendine dedi ki: "Bunlarla danışayım, muhakkak ki bunlar gücümü kuvvetimi gevşetirler, beni zayıf düşürürler. Bunların boğazına düşkün olmaları, yiyecek sevgisi, tembellikleri, bilgisizlikleri de bana da sirayet eder." Akıllı balık, arkadaşlara danışmadan tehlikeli olan yerden uzaklaştı ve nûr denizine kadar gitti. Çok zahmetler çekti. Fakat sonunda eminlik yurduna, selâmet diyarına kavuştu. Yarım akıllı balık bunu gördü, ağzının tadı kaçtı. "Eyvah!” dedi. "Ben firsatı kaçırdım. Nasıl oldu da akıllı arkadaşa yoldaş olamadım. Ama şu anda onu düşünmeyi bırakayım da kendi kendime bir çare bulayım” dedi. O da ölü taklidi ederek kurtuldu. Diğer balık ise, canını kurtarabilmek için sağa sola sıçrayıp kurtulmayı denedi. Ama balıkçıların ağından kurtulamadı. Balık ağ içinde kaldı. Böylece ahmaklık onu ateşin üstüne attı. Ateş üstünde bir tavanın içinde ahmaklığı yüzünden yanmaya, kızarmaya mecbur oldu. Allah'a ve O'nun peygamberlerinin getirdiği dine inanmayanlar da ahmaklıklarından cehennemde böyle olacaklardır. O, yakıp kavuran ateşin harareti ile yanıp yakılırken akıl ona; "sana bir haberci ya da hâlden korkutucu gelmedi mi?" diyordu. "Evet, geldi" diyordu. Ve yine o balık diyordu ki: "Bu boyun kıran mihnetten, bu işkenceden kurtulsam, denizden başka yurt edinmem, gölde, gölcükte yurt tutmam. Uçsuz bucaksız olan nûr denizini ararım; esenliğe ulaşırım, orda ebedî olarak sağlıkla selâmetle ömür sürerim."

Kelile ve Dimne ile Mesnevî' deki bu iki hikâyenin ortak konu ve motifleri açısından değerlendirilmesi:

a. Mevlânâ'nın, Mesnevî' sindeki birçok masal ve hikâyeyi Kelile ve Dimne'den aldığı görülür. Mesnevî'de: “Kelile'de okumuşsundur.” sözünden anlaşılacağı üzere Mevlânâ'nın Kelile ve Dimne'yi gördüğü ve okuduğu anlaşılmaktadır.

b. Mevlânâ Mesnevî'de: "O kabuktan ibarettir, bu anlatışımızsa canın tâ içidir." İfadesiyle masalın Kelile ve Dimne'deki şeklini sade, basit bulduğu, oysaki kendisinin bu masalı cana işleyecek, ruhları harekete geçirecek; insana, insanlığını ve Müslümanlığını hatırlatacak bir öze sahip olduğunu anlatmak ister.

c. Her iki hikâyede de benzer başlıklar, konular ve motifler görülür. Bunlar: Kelile ve Dimne'de "üç balık"; Mesnevî'de "üç balığın halleri ve sonları" adı altında kullanılan başlıklardır. Üç balık ise, bir motiftir. Üç balığa yüklenen görevler de benzerdir. Dirayetli olan önceden davranan ve hazırlık sahibi kimseyi tanımlar. Bir musibetle karşılaşacağı olayı önceden bilir ve onun bir 
çaresini bulur. Böylelikle hadiseyi vukudan önce defeder. Âcize gelince; o tereddüt, temenni ve oyalanma içinde olur, nihayet helâke maruz kalır. Üç balığın başından geçen olayların akıbeti ve halleri manidardır. Yalnız her iki hikâyede olayların aktarış biçimi farklı olmasına rağmen verilmek istenen mesaj aynıdır. Şairin aynı inanç ve düşünce dünyasına sahip olması bunda etkilidir.

d. Hikâyelerdeki olay yeri; göl ve gölün etrafında yaşanmıştır.

e. Kelile ve Dimne'deki masalın sadece olay aktarımı şeklinde yansıtıldığ görülür. Yani Beydebâ üç balığın halleri ve düştükleri durumu anlatır ve geçer. Üç balığın durumla ilgili nasihatvâri bir tavır takınmaz. Belki onun bu yöndeki tavrını olay örgüsünden önceki cümlelerden aramak gerekir. Mevlânâ ise; Allah'a ve O'nun peygamberlerinin getirdiği dine inanmayanların da ahmaklıklarından cehennemde böyle olacaklarını ifade ederek uyarıcı düşüncesini olay örgüsünün içine ve sonuna yerleştirir.

f. Beydebâ, hikâyedeki bir olayı hükümdarların dirayetli, ileri görüşlü olmaları gerektiği yolundaki bir anlatım üzerine bina eder; Mevlânâ hikâyede, "uçsuz bucaksız olan nûr denizini ararım; esenliğe ulaşırım, orda ebedî olarak sağlıkla selâmetle ömür sürerim" diyerek olayı dinî, tasavvufî bir alana çekerek, görüşlerini balıkların üzerinden aktarır.

g. Mevlânâ, Mesnevî'de hikâye anlatmadaki maksadını şöyle izah eder: "Maksadım sizlere hikâye anlatmak değil, kıssadan hissedir." Mevlânâ'nın bu yolu tercih etmesinin sebebi geniş halk kesimleri tarafından anlaşılır olmasını istemesidir. Bu hikâyede de onun Müslüman halka anlayacağı dilde hitap etme, onları uyarma isteğinin yansımaları görülür.

h. Mevlânâ, metinde birtakım ekleme ve çıkartmalar yapmıştır. Ancak bunlar öze hitap eden değişiklikler değil, daha çok anlatımla ilgili değişikliklerdir. Şairin hikâye sonunda, hikâyedeki olay örgüsü ile uyumlu düşüncelerini ilettikleri görülmektedir. Her iki hikâyede de balıkların her biri için farklı benzetmelerde bulunulmuştur. Bunlar hikâyede; akıllı (yarım akıllı), aha akı1lı ve âciz gibi ifadelerle balıklar nitelendirilmiştir. Mevlânâ'nın metninin anlatım olarak daha canlı olduğu görülmektedir. Bu özellikle metne eklenen sıfatlar ve zarflar, bir de aynı duygu ve düşünceyi anlatan cümlelerin daha uzun olarak aktarılması ile sağlanmıştır.

\section{Mesnevî’de Kelile ve Dimne'nin Zikredildiği Hikâyeler}

Mesnevî'de Kelile ve Dimne'nin doğrudan zikredildiği üç hikâye tespit edilmiştir. Bu hikâyeler: "Av hayvanlarının arslana tevekkülü ve terk-i sa'yi söylemesi, ana karnında Yahyâ (a.s.) [nın] Îsâ (a.s.) [a] secde etmesi ve gölcük, gölcükte balık avlayanlar. Biri akıllı, öbürü yarım akıllı, ötekiyse hiçbir şey olmayan kendini beğenmiş ahmak, gaflete düşmüş üç balık ve bunların sonları" dır. Tespit edilen bu hikâyelerden yola çıkarak, Mevlânâ'nın Mesnevî'sinde yer alan hikâyelerin bazılarında Kelile ve Dimne etkisi olduğu anlaşılmaktadır. Doğrudan zikredilen bu üç hikâyenin ayrıntılı incelenmesi hikâyelerin karşılaştırılması ve değerlendirilmesi 
kısmında ele alınmıştır. Aşağıda bahsi geçen hikâyeler, Mesnevî’den olduğu gibi aktarılmıştır.

912. ${ }^{1}$ Kelile'de o kıssayı tekrar oku ve o kıssa içinde de hisseyi talep et!

"Hind hükemâsından birinin, hanların lisânından nesâyıh icrâsına dair tertîp etmiş olduğu Kelile ve Dimne namındaki kitapta münderic olup, âtîde nakl edecek hikâyeyi tekrar oku ve ondan hisse al ki, kalp altını boyayan tavşana müşâbih bulunan sahte mürşidler seni doğru yoldan alıkoymasın ve arslanı kuyuya düşüren eğri hayale giriftâr olmıyasın." (Konuk 2007: 298).

\subsection{Hikâye: "Av hayvanlarının arslana tevekkülü ve terk-i sa'yi söylemesi."}

913. Av hayvanlarından bir tâifeye hoş vâdîde dâima arslandan 1ztırâp var idi.

913. O kadar çok ki o arslan pusudan kapardı; o otlak hepsinin üzerine nâhoş olmuş idi.

915. Çare düşündüler; arslana geldiler, dediler ki: Biz seni vazifeden tok tutarız.

916. Bu mer'a bize acı olmamak için, sen vazifeden gayri bir avın ardınca gelme! (Konuk 2007: 299).

"Hayvanlar şu çareyi buldular: Arslana huzuruna gidip dediler ki: Biz senin nafakanı ta'yin ettiğimiz bu nafakadan başkaca apansızın pusudan çıkıp av arkasında koşma ve bu mer'yı bize zehir gibi acı etme!"

“Av hayvanlarının arslana, Tanrı’ya dayanmasını, çalışmaktan vazgeçmesini söylemeleri”

"Av hayvanları, güzelim bir ovada yayılıyorlardı ama arslanın korkusundan da k1vranıp duruyorlardı.

Çünkü arslan boyuna pusudan çıkıp birini kapıyordu. Bu yüzden o otlak zehir kesilmişti onlara.

Düzene başvurdular; arslana geldiler, dediler ki: Biz, sana her gün ne yiyeceksen getirir, veririz, doyururuz seni. Bundan sonra avlanmaya kalkışma; bir av peşine düşme de şu otlak zehir olmasın bize.” (Gölpınarlı 1989: 233).

\subsection{Hikâye: "Ana karnında Yahyâ (a.s.)nın Îsâ (a.s.)a secde etmesi."”}

Hind nüshalarında bu unvan "Yahyâ ve Mesîh'in ana karnında birine secde etmesi" sûretinde mündericdir.

3593. Kendinizin vaz-1 hamlinden daha evvel Yahyâ'nın validesi Meryem'e gizlice dedi.

3594. Ki: "Yakînen gördüm; senin içinde bir şah vardır ki, o ülü’l-'azm bir resûl-i âgâhtır."

\footnotetext{
${ }^{1}$ Mesnevî’de hikâyelerin her satır başları bu şekilde numaralandırılmıştır.
} 
3595. "Ben sana mukâbil vâk’i olduğum vakit, benim hamlim derhal secde etti!"

Bazı nüshalarda ... yerine ... vâk’i olmuştur. "Ey zeyreklikler sahibi!” demek olur.

3596. "Bu cenin o cenine secde etti ki, onun sücûdundan vücudundan ağrı vâk'i oldu."

3597. Meryem, "Ben de kendi içimde bu karındaki çocuktan bir secde gördüm" dedi. (Konuk 2007: 465).

Bu kıssa üzerine işkâl getirmek. (Konuk 2007: 466).

Bu unvan Hind nüshalarında "cahilin bu kıssa üzerine işkal getirmesi” sûretindedir. Yani, "cahiller bu kıssayı efsane addederler ve vukuuna imkân görmezler" demek olur.

3598. Ahmaklar derler ki: "Bu efsaneye çizgi çek, zira yalandır ve hatadır!"

Hakikat-1 eşyadan cahil ve gafil olan ahmaklar derler ki: "Bu kıssa efsanedir ve masaldır. Sen bu efsane üzerine bir iptal çizgisi çek. Zira biraz muhakeme edilirse yalan ve yanlış olduğu meydana çıkar!"

3599. "Zira ki Meryem kendi hamlinin vaz'1 vaktinde yabancidan ve hem de akrabasından uzak idi."

3600. "O füsunu tatlı olan, fariğ olmadıkça şehrin haricinden içeriye gelmedi." "Füsun", mekr ve tedbir ve hile ve tezvir manalarına da gelir. "Füsunu tatlı ve latif olmak", Hz. Meryem'in hârikul'âde bir sûrette Hz. Cibril'in nefhinden vâk'i olan hamli üzerine nazar-1 halktan uzaklaşmak tedbir ve hilesinden ibarettir. Yani, "O hoş tedbirli olan Hz. Meryem, hamlinden fariğ olmadıkça ve Îsâ (a.s.)1 doğurmadıkça şehrin haricinden şehrin içine gelmedi." Nitekim kıssası Kur'an-1 Kerîm'de Sûre-i Meryem'de mezkûrdür.

3601. "Yahyâ (a.s.)1n anas1 mekân-1 baîdde olan Hz. Meryem'i nerede gördü ki, ona macerada yani kıssada zikrolunan bu sözü söyleyebilsin?” Zira Hz. Meryem kavim ve kabilesinden tağayyüb etmiş idi. Binâenaleyh, şu muhakemeye nazaran bu k1ssa yalan bir efsanedir.

İşkâlin cevab1. (Konuk 2007: 467-470).

3602. "Bunu o kimse bilir ki, ehl-i hatırdır. Afakın gaibi onun için hazırdır. "Eh-i hatır"dan murad, kalbi gözü alıp, esrar-1 gaybiyyeyi müşahede eden zevattır. Yahyâ (a.s.)1n validesi, Zekeriyyâ (a.s.)1n zevce-i muhteremesidir ki, onun hamli de Zekeriyyâ (a.s.)ın reculiyyetten inkıtâ'ından sonra min-tarafillah harika nev'inden olarak vâki' oldu. Nitekim Kur'ân-1 Kerîm'de Sûre-i Meryem'de ve Sûre-i Bakara'da kıssası mezkûrdür. Ve Hz. Meryem bir veliyye-i kamile idi. Binâenaleyh, gerek Yahyâ (a.s.)1n gerek Hz. Meryem ehl-i dilden idiler. Ve ehl-i dil indinde gaib ve hazır müsavidir. İmdi Hz. Meryem Yahyâ (a.s.)1n validesini tahattur etse, mekân-1 baîdde olsa bile müşahede edilebilir idi. Uzak yerdeki 
eşyanın görülmesi ve seslerin işitilmesi mümkün olduğunu bugün fen de ispat ediyor. Ve vasita-i rü’yet ve istimâ' ma'lûm olduğu için, bugün inkâr olunamıyor. Halbuki insanın vücudunda bu hassalar bizzat mevcuttur. Ât-1 fenniyyenin vücuduna hacet olmaksızın dahi mümkündür. Yalnız bu gibi esrâr-1 gaybiyyenin kendi vücudunda inkişafı için icab eden şeraiti hâiz olmak icap eder. O şerait dahi velayetin levazımındandır. Âlem-i kesafette müstağrak ve ıstıfadan uzak olanlar, mahza kendi vücutlarında böyle bir şey göremedikleri için, cehillerinden inkâr ederler."

3603. "Meryem'in önünde nazarda hazır gelir. Yahyâ'nın anası ki, basardan uzaktır. Zahiren basar-1 hissiden uzak olan Yahyâ (a.s)ın validesi, ehl-i dilden olan Hz. Meryem'in önünde nazar-1 kalbide hazır görünür. Nitekim yukarıda izah olundu."

3604. "Kapanmış gözler dostu görür, madem ki postu müşebbek etmiş ola. Âlem-i kesafete ve cismaniyyete kapanmış olan his gözleri, mücahede ve riyazet sebebiyle telattuf edip ruhaniyyet mertebesini bulan ve kalbur gibi delik deşik olmuş bu cisim içinde vücud-1 misalisi ve berzahisi ile görmek istediği yarini ve dostunu, uzak mesafede olsa bile o deliklerden görür."2 (Konuk 2007: 468-476).

5.3. Hikâye: "Gölcük, gölcükte balık avlayanlar. Biri akıllı, öbürü yarım akıllı, ötekiyse hiçbir şey olmayan kendini beğenmiş ahmak, gaflete düşmüş üç balık ve bunların sonları".

"A inatçı, bu, içinde üç büyük balık olan gölcügün hikâyesi gibidir hani.

Kelile'de okumuşsundur, fakat o hikâyenin kabuğudur; buysa canın da özü.

Birkaç balıkçı, o gölcüğün bulunduğu yerden geçerlerken içindeki balıkları gördüler.

Hemen ağ getirmeye koştular. Balıkların akılları başlarındaydı; işi anladılar.

Akıllı balık, hemen yolu tuttu, o güç aş1lır yolu ister istemez aştı.

Bunlarla danışmayayım, yoksa mutlaka bunlar gücümü, kuvvetimi gevşetirler; onların hem yiyecek- yem sevgisi, içlerinden coşar, kaynar; tembellikleri, bilgisizlikleri bana da sirayet eder dedi. Danışacaksan bir diriyle danış ki seni de diriltsin; ama nerde o diri?” (Gölpınarlı 1989: 312-313).

2220. "A yolcu, yolcuyla danış; fakat kadının vereceği akıl, ayağını topal eder.

Yurt sevgisinden de dem vurma, durup dinlenme; bil ki yurt o yandadır a benim canım bu yanda değil.

Yurt istiyorsan o ırmağın o yanına geç; şu doğru sözü az yanlış oku. (Gölpınarlı 1989: 313).

\footnotetext{
${ }^{2}$ Devamı için bkz: (3605-3614.) beyitler.
} 
Abdest alanın, abdest duâlarını okumasının sırrı (Gölpınarlı 1989: 313-314).

Abdestte her uzuv yıkanırken ayrı bir duâ vardır; hadiste her bir uzuv için bir duâ buyrulmuştur. Burnuna su verirken Ganî Rab'den cennet kokusunu iste.

İste de o koku, seni cennetlere çeksin; gül kokusu, gül bahçesine k1lavuzdur. Pislikten arınırken de virdin, sözün, Yârabbi, sen beni şu pislikten arıt sözüdür.

Elim dersin, buraya ulaştı ancak, bunu yıkayıp arıtı; ama canı yıkayıp arıtmakta elim gevşek. A Tanrım, adam olmayanların canları bile lütfunla adam oldu; lütuf elin canlara erişir. Aşağılık biriyim ben, benim başarabileceğim ancak bu; o yanı da sen arit ey kerem sahibi."

2280. "Ey Tanrım, ben pislikten dışımı arıttım; iç pisliklerden de bu dostu sen yıka, sen arit."

\section{Mesnevî ile Kelile ve Dimne Arasındaki Benzer Hikâyeler}

\subsection{Hikâyelerin Karşılaştırılması ve Değerlendirilmesi}

Kelile ve Dimne ile Mesnevî'deki benzer masallar karşılaştırılıp incelendiğinde, tespit edilen başlıca hikâyeler şu şekildedir:

1. Hikâye: "Tilki ve karakaçan hikâyesi ile arslan, tilki ve eşek" adlı hikâyelerdir.

1.1. Kelile ve Dimne'deki Şekli: Ad1 "tilki ve karakaçan" dır. (Arslan yemekten önce banyo yapmak ister. Tilki sadece eşeğin ciğerini yer.) (Alpay 1973: 205209).

1.2. Mesnevî’deki Şekli: Adı yoksa da "arslan, tilki ve eşek" denilir. (Arslan yemek sirasında su içmeye gider. Tilki eşeğin ciğerini yer.) (Karaismailoğlu 2004: 236).

Kelile ve Dimne ile Mesnevî'deki bu iki masalın benzerlikleri ve farklılıkları açısından değerlendirilmesi:

a. Kelile ve Dimne'de "tilki ve karakaçan" başlığı ile Mesnevî'deki "arslan, Tilki ve eşek" başlıkların benzer olduğu görülür. Hikâyede geçen karakterler sahip olduğu görev bakımından da benzerlik taşır. Her iki hikâyede de karakterler, ciğerin peşindedir. Eşeği, oyunlarına çekmeleri dikkat çekicidir.

b. Hikâyelerde Beydebâ ve Mevlânâ'nın vermek istedikleri mesajlar birbiriyle benzerlik taşır. Olay örgüsünü ise, hayvanlar üzerinden anlattığı görülür. $\mathrm{Bu}$ hayvanlar: Aslan, tilki ve eşektir.

c. Her iki hikâyeyi incelediğimizde, bu hikâyelerin temelde aynı temalar üzerinden şekillendiğini görmekteyiz. Eşeğin katmerli ahmaklı̆̆g, tilkinin kurnazlığı ve bunun sayesinde hem arslanı hem de eşeği türlü hileleriyle oyuna getirmesi, arslanın hem hastalıktan hem de fillerle savaştığı için yorgun düşmesi, güçsüzlüğ̈̈ ve aceleci tavırları ile arslanın ilk denemede başarısızlığın 
yanı sıra, tilkinin hedeften şaşmaması ve eşeği kandırmak düşüncesi her hikâyede de benzer olup farklı şekillerde tezahür etmektedir.

d. Tilki, her iki hikâyede de eşeğin ciğerini yemiştir. Hikâyede geçen ana düşünce aynı olup; hâkim düşünce ise, tilkinin kurbanlarını kandırmasıdır. Olay yeri, ormanda yaşanmıştır.

e. Hikâyenin sonunda, hikâyedeki olay örgüsü ile ilgili düşüncelerini iletirler. Kelile ve Dimne hikâyesinde tilki, arslana eşeğin ciğerinin olmadığını fakat etiyle karnını bir güzel doyurabileceğini söylerken; Mesnevî'de tilki, eşekte hiç ciğer ya da yürek olsaydı buralara kadar gelir miydi diye cevap vermiştir.

2. Hikâye: "Aldatan tavşan hikâyesi ile av hayvanlarının arslana tevekkül etmesini ve çalışmayı bırakmasını söylemeleri” adlı hikâyelerdir.

2.1. Kelile ve Dimne'deki Şekli: Adı "aldatan tavşan" dır. (Ormandaki hayvanların arslanın zulmünden dolayı çektiği korku ve cefadır.) (Alpay 1973: 78-79).

2.2. Mesnevî’deki Şekli: “Av hayvanlarının arslana tevekkül etmesini ve çalışmayı bırakmasını söylemeleri” dir. (Av hayvanlarının arslanın hiddetinden, korkusundan çektiği sıkıntılardır.) Kelile'den şu hikâyeyi araştır ve bu kıssadan hisse al. (Karaismailoğlu 2004: 82-86-92-94-96-97-101-105-109110).

Kelile ve Dimne ile Mesnevî'deki bu iki masalın benzerlikleri ve farklılıkları açısından değerlendirilmesi:

a. Kelile ve Dimne ile Mesnevî'deki bu hikâye incelendiğinde; "Kelile'den şu hikâyeyi araştır ve bu kıssadan hisse al.” diyerek Mevlânâ, böyle bir hikâyenin aslını birde Kelile'den okunması gerektiğine vurgu yapar.

b. Mevlânâ Mesnevî'de, kendi fikirlerini aktarmak için pek çok hayvandan bahseder. Kelile ve Dimne'de geçen, Mesnevî'de yer alan bu arslan, padişah olarak tanımlanır. Ayrıca arslan hem av hayvanlarını rahatsız eder hem de onlardan günlük yemek ihtiyacını karşılar.

c. Hikâyenin, Mesnevî ile Kelile ve Dimne'de yine aynı şekilde bir olay aktarımı üzerinden yansıtıldığ görülür. Tavşan karakteri üzerinden gerçekleştirilen olay örgüsü, yine küçük bir hayvanın kendi zekasını kullanarak koca bir hayvanı nasıl yendiğini anlatılır. Tavşan ile arslanın arasındaki mücadelenin anlatıldı̆̆ 1 bu hikâye, zayıf bir hayvanın güçlü bir hayvanı zekasıyla halt edeceğini ispatlar.

d. Mesnevî' de; tavşanın av hayvanlarına "Ey dostlar! Hak bana ilham verdi. Zayıf bir kişinin güçlü bir fikri oldu" demesi üzerine Mevlânâ'nın olayı; dinî ve tasavvufî bir alana çekerek, görüşlerini tavşanın üzerinden aktardığı anlaşılır.

e. Her iki hikâyenin sonunda da arslanın kuyuya bakması ve arslanın kuyuda o tavşanın aksini görmesi üzerine, kuyuya atlaması ve arslanın ölmesidir. Kelile ve Dimne'de bu olay sonucu av hayvanlarının arslanın şerrinden kurtulması ile sonlanırken; Mesnevî' de ise, arslandan kurtulmasının yanı sıra tavşanın tüm bu olaylara rağmen yine de tedbîri elden bırakmamasına vurgu yapar. 
f. Kelile ve Dimne'de olay yeri, Bağdat çevresindeki güzel bir ormanda yaşanırken; Mesnevî' de ise, güzel bir ovada geçmektedir.

g. Kelile ve Dimne'de insanlara iyi ahlâk ve akıl mesajları verilmektedir. Mesnevî'de ise, olayı tasavvufî bir alana çekerek, görüşlerini dinî bir çerçeve üzerinden aktarır.

3. Hikâye: "Bülbül ile bağcı hikâyesi ile kaza gelince aydın gözlerin bağlandığını anlatan Hüdhüd ve Süleyman'ın-Allah'ın selamı üzerine olsun" adlı hikâyelerdir.

3.1. Kelile ve Dimne'deki Şekli: Adı "bülbül ile bağcı" dır. (Alpay 1973: 87-88).

3.2. Mesnevî'deki Şekli: "Kaza gelince aydın gözlerin bağlandığını anlatan Hüdhüd ve Süleyman'1n-Allah'ın selamı üzerine olsun.” hikâyesidir. (Karaismailoğlu 2004: 102-103).

Kelile ve Dimne ile Mesnevî'deki bu iki masalın benzerlikleri ve farklılıkları açısından değerlendirilmesi:

a. Kelile ve Dimne ile Mesnevî'deki bu hikâyeler incelendiğinde; hikâyelerde, kaza ve kaderin insan hayatındaki rolü vurgulanır. Çünkü ele alınan bu hikâyelerinin ortak noktası; kaza ve kadere imandır. Aynı zamanda kaza ve kaderin hükmünü inkârı da küfre girmektir. Hikâyeden de anlaşıldığı gibi bir insanın nasibinde yer yoksa en ufak bir örtü altında bile olsa, onu görmesi mümkün değildir. "Gözleri bağlanmış” ifadesi özellikle bu durumu izahı için kullanıldığı anlaşılır.

b. Kelile ve Dimne'de anlatıldığı gibi "Dostum! Kaza ve kader hükmünü gösterecek olduktan sonra, ne kadar tedbirli olmuş olsan boştur." sözü ile hikâyedeki bülbülün aslında ne anlatmak istediği dile getirir. O Bülbül ki yer altında saklı gizli hazineyi bilen yine o bülbül ki kaderin hükmü ile otlar arasındaki kapanı görmez. Kaza ve kadere işaret eder.

c. Mesnevî'de, bülbül yerine Hüdhüd yer alır. Hüdhüd, yerin derinliğindeki suyun dibini bile gördüğünü dile getirip ancak toprak altındaki tuzağı fark edemediğini söyler. Mesnevî'de bu durum, olayın kurmaca boyutundan soyutlanarak dinî bir boyuta çekildiği anlaşılır. Öyle ki Hz. Süleyman'a telmihte bulunması bunun bir kanitıdır.

d. Kelile ve Dimne'de: "hüküm ve kazaya karşı ne kadar açıkgöz olsa, kör olur"; Mesnevî'de ise, "kaza gelince bilgi uykuya dalar, ay kararır, güneş tutulur" gibi ifadelere yer verildiği görülür. Her iki hikâyeden anlaşılacağı üzere, yine kaza ve kadere dikkati çekerek dinî ve tasavvufî boyuta bir gönderme yapılır. Ayrıca kaderin aklın gözünü örtmesi ve Hüdhüd'ün buna razı oluşu dile getirilir.

e. Olay yeri, Kelile ve Dimne'de Bir bağcının bağında yaşanırken; Mesnevî'de ise, Süleyman'ın çadırında geçmektedir.

f. Kelile ve Dimne'de; bağcı bir kapan kurarak bülbülü tuttu. Kafese koyup hapsetti. Mesnevî'de ise, Hüdhüd'ün tuzağa yakalanması ve kafese umutsuzca 
girişi anlatılır. Her iki hikâyede tuzak ve kafes gibi ifadelerinin ortak olarak kullanıldığı görülür.

4. Hikâye: "Behruz adlı tavşan hikâyesi ile tavşanların hikâyesi: Tavşanlar, "ben gökyüzündeki ayın sana "şu su pınarından sakın demek üzere elçisiyim" söyle diye bir tavşanı bir file gönderdiler. Nitekim Kelile ve Dimne'de tam olarak anlatılır."

4.1. Kelile ve Dimne'deki Şekli: Adı "Behruz adlı tavşan" dır. (Alpay 1973: 172173).

4.2. Mesnevî’deki Şekli: Tavşanların hikâyesi: Tavşanlar, "ben gökyüzündeki ayın sana "şu su pınarından sakın demek üzere elçisiyim" söyle diye bir tavşanı bir file gönderdiler. Nitekim Kelile ve Dimne'de tam olarak anlatılır. (Karaismailoğlu 2004: 576-577).

Kelile ve Dimne ile Mesnevî'deki bu iki masalın benzerlikleri ve farklılıkları açısından değerlendirilmesi:

a. Mesnevî'de belirttiği gibi "nitekim Kelile ve Dimne'de tam olarak anlatılır" ifadesiyle Kelile ve Dimne'yi işaret ettiği anlaşılır.

b. Kelile ve Dimne ile Mesnevî'deki bu masal karşılaştırıldı̆̆ında, hikâyelerin ana karakteri tavşandır. Her iki hikâye; tavşan gürûhunu, fillerin hücumundan kurtarmış olan akı1lı ve bilgeli bir tavşandan bahseder.

c. Kelile ve Dimne'de tavşanların bir padişahının olduğu ve bu padişahında bir veziri olduğu anlatılır. Vezirin adı ise, Behruz adında bir tavşandır. Hikâyede tavşanın zekâ ve anlayışta eşi benzeri olmadığı anlatılırken; Mesnevî’de ise, tavşanın, "ben, ayın elçisiyim ve onunla eşim" demesinden bahseder.

d. Kelile ve Dimne'de Behruz gibi akıllı bir karakterin seçilmiş olmasına işaret ederek, aynı zamanda seçilmiş olan bu reisin kendileri üzerinde de hâkim olacağını hatırlatarak bunun önemini belirtir. Mesnevî' de ise, yaşlı bir tavşana işaret etmektedir. Bu da gösteriyor ki Mevlânâ, yaşanmışlık tecrübesine dikkati çekerek yine burada aklı ön planda tutmuştur.

e. Olay yeri, Kelile ve Dimne'de bir pınar başında yaşanırken; Mesnevî'de ise, havuz başında geçmektedir.

f. Mevlânâ, bu hikâye ve motiflerde birçok konulara temas etmiş tasavvufî, dinî, felsefî, ahlâkî ve terbiyevî düşüncelerini ve görüşlerini bazen bir hikâye ile, bazen de bir veya birkaç beyitlik motiflerde telmihte bulunarak anlattığı görülür. Fil o gece hortumunu suya vurunca su dalgalandl ve ay titredi. $\mathrm{Hz}$. Peygamberin ayı ikiye bölme hadisesine telmihte bulunmuştur. Hikâye; insanhayvan, iç-dış benzerliklerinden ve münasebetlerinden teşbihlerden izah eder.

g. Mevlânâ, Mesnevî'de aynı olayı aktarırken hikâyeden ziyade insanların bu hadiselerden ögüt alarak ders çıkarmaları gerektiğine dikkati çeker. Mesnevî'de, fil hortumunu suya vurunca su dalgalanır ve ay titrer. Ay pınarın içinden titreyince fil, onun o sözüne inanıp ve oradan uzaklaşırken; Kelile ve Dimne'de ise, havuzun başında su içmek isteyen fil padişahının, ayın titremesi durumu karşısında şaşırıp, herkesi toplayıp ve oradan ayrıldı̆̆ından bahseder. 


\section{Sonuç}

Klasik Fars edebiyatının en büyükleri arasında yer edinen Mevlânâ, büyük bir sûfi olmasının yanı sıra bir eğitmen ve öğretmen olarak büyük şahsiyetlerdendir. Türk edebiyatında Mesnevî denince akla ilk önce Mevlânâ'nın altı ciltlik eseri gelir. Mesnevî’de tasavvufî anlayış çeşitli hayvan hikâyeleri ile anlatılır. Bu hikâyeler, insanın eylem ve tecrübelerini temsil eder.

Mevlânâ Mesnevî’de, şiir yolu ile kendini Allah yoluna adayanlara rehber olmayı amaçlar. Şiiri bir amaç olarak görür. Bu bakımından içeriğe önem verir. İçerikte dinî ve din usûllerini anlatır. Okuyucunun hakikatte ise, kendisinin bulması istenir.

Eserde öyküler vardır. Öyküler, insanı temsil eder. Bu yüzden anlatılan olay insan yaşamına uygun olarak aktarılır. Ayrıca hikâye pekiştirilmek amacıyla başka hikâyelere dayandırılır. Bu yüzdendir ki Mevlânâ bazı hikâyelerine "Kelile ve Dimne'de tam olarak şöyle geçmektedir." diye vurgu yapar. Buradan Mevlânâ'nın Kelile ve Dimne'yi gördüğü, okuduğu anlaşılır.

Beydebâ Kelile ve Dimne'de, “Bin bir Gece Masalları”nda olduğu gibi iç içe girmiş çerçeve hikâyelerden eseri oluşturur. Her bölümde bir çerçeve hikâye, onun içinde de hikâyecikler, manzum hikmetler vardır. Gerçekle düşün yer yer birbirine karıştı̆̆1, düşündürücü olduğu kadar da eğlendirici olan Kelile ve Dimne bir yanıyla da masal kitabıdır.

Mevlânâ'nın Mesnevî'sinde tespit edilen hikâyelerden yola çıkarak, yer alan hikâyelerin bazılarında Kelile ve Dimne etkisi olduğu açıkça anlaşılır. Mesnevî ile Kelile ve Dimne'de ortak kahramanlara yer verildiği görülür. Bu kahramanların akıllı, bilgili ve ahlâklı oluşu da dikkati çeker. Hayvan karakterlerinden yola çıkarak insanlara birtakım iletiler verir. Verilmek istenen mesaj Mesnevî'de dinî tasavvufî ve felsefî olarak yansitılırken; Kelile ve Dimne'de ise, daha çok bir kurgu niteliği taşır. Ayrıca ele alınan kahramanların küçük ve zayıf hayvanlardan seçilmiş olması, sonrasında ise bu kahraman hayvanların çok büyük işleri başardıkları tespit edilir.

Beydebâ, hikâyedeki olayları hükümdarların dirayetli, ileri görüşlü olmaları gerektiği yolundaki bir anlatım üzerine bina eder; Mevlânâ ise, olayı dinî, tasavvufî bir alana çekerek, görüşlerini aktarır. Hikâyelerinde yer yer telmihte bulunur. Ayrıca hikâyelerde ortak temalar tespit edilir. Öğretici yönü ağır basar. Hikâyeden ziyade insanların bu hadiselerden öğüt alarak ders çıkarmaları gerektiğine dikkati çeker.

\section{Kaynakça}

Alpay, Selahaddin, (1973). Kelile ve Dimne, Bedir Yayın Evi, İstanbul.

Aytaç, Gürsel, (2001). Karşılaştırmalı Edebiyat Bilimi, Kültür Bakanlı̆̆ı Yayınları, Ankara. 
Brockelman, Carl, (1977). Kelile ve Dimne, TDV İslam Ansiklopedisi, (VI.), M.E.B. Yayınları, İstanbul.

Çapan, Pervin (2003). Ali Şir Nevâŷi ve Fuzûlî̀nin Leylâ ve Mecnûn Mesnevîlerinin Anlatım Tarzlarının Mukayeseli Tahlili, I. Uluslararası Karşılaştırmalı Edebiyat Kongresi, Osmangazi Üniversitesi, Eskişehir.

Enginün, İnci (1999). Mukayeseli Edebiyat, Dergâh Yayınları, İstanbul.

Gölpınarlı, Abdülbâki, (1992). Mevlânâ Celâleddîn-i Rûmî; Dîvân-ı Kebîr, (I-VII); (1989). Mesnevî ve Şerhi, (I-II-III-IV), Kültür Bakanlığı Yayınları, Ankara.

İzbudak, Veled, (1991). Mesnevî, (I-VI), M.E.B. Yayınları, İstanbul.

Karaismailoğlu, Adnan, (2004). Mesnevî Hikâyeleri, (III), Akçağ Yayınları, Ankara.

Karaismailoğlu, Adnan, (1986). Mevlânâ Celâleddîn-i Rûmî, (I-II), Kültür ve Turizm Bakanlığı Yayınları, Ankara.

Karaismailoğlu, Adnan, (2002). Kelile ve Dimne, İslam Ansiklopedisi, M.E.B. Yayınları, Ankara.

Konuk, Ahmed Avni, (2007). Mesnevî-i Şerîf Şerhi, (I-IV-VI-VIII), Kitabevi Yayınları, İstanbul.

Mengi, Mine (2005). Dîvân Şiirinde Metinlerarası İlişkiler, Şinasi Tekin ’in Anısına "Uygurlardan Osmanlyya", Simurg Yayınları, İstanbul.

Toska, Zehra, (1989). Türk Edebiyatında Kelile ve Dimne Çevirileri ve Kul Mes 'ûd çevirisi, (I-inceleme, II-edisyon kritik), İstanbul.

Tuğluk, İbrahim Halil (2009). Mesnevîlerde Şairlerle İlgili Bazı Tespitler, Turkish Studies, 4(7), Doi: http://dx.doi.org/10.7827/TurkishStudies.921.

Tuğluk, İbrahim Halil (2020). "Hızırzâde Mehmed Fevzî Efendi Bahâristân Tercümesi”, Efe Akademi Yayınevi, İstanbul. 